\title{
Sociodemographic and nutritional correlates of neurobehavioral development: a study of young children in a rural region of Ecuador
}

\author{
Alexis J. Handal, ${ }^{1}$ Betsy Lozoff, ${ }^{2}$ Jaime Breilh, ${ }^{3}$ and Siobán D. Harlow ${ }^{1}$
}

Suggested citation

Handal AJ, Lozoff B, Breilh J, Harlow SD. Sociodemographic and nutritional correlates of neurobehavioral development: a study of young children in a rural region of Ecuador. Rev Panam Salud Publica. 2007;21(5):292-300.

ABSTRACT Objective. To identify and describe the sociodemographic and nutritional characteristics associated with neurobehavioral development among young children living in three communities in the northeastern Andean region of Cayambe-Tabacundo, Ecuador.

Methods. Women in the study communities who had a child 3 to 61 months of age completed a questionnaire about maternal and child health and sociodemographic characteristics. The Ages and Stages Questionnaire (ASQ) was directly administered to 283 children by two trained interviewers. Growth measurements and a hemoglobin finger-prick blood test were obtained in 2003-2004. Prevalence of developmental delay was calculated, and associations between child development and maternal, child, and household characteristics were explored.

Results. High frequencies of developmental delay were observed. Children 3 to 23 months old displayed delay in gross motor skills $(30.1 \%)$, and children 48 to 61 months old displayed delay in problem-solving skills (73.4\%) and fine motor skills $(28.1 \%)$. A high frequency of both anemia $(60.4 \%)$ and stunting $(53.4 \%)$ was observed for all age groups. Maternal educational level was positively associated with communication and problem-solving skills, and monthly household income was positively associated with communication, gross motor, and problem-solving skills.

Conclusions. The results suggest a high prevalence of developmental delay and poor child health in this population. Child health status and the child's environment may contribute to developmental delay in this region of Ecuador, but sociodemographic factors affecting opportunities for stimulation may also play a role. Research is needed to identify what is causing high percentages of neurobehavioral developmental delay in this region of Ecuador.

Key words Epidemiology, child development, population characteristics, socioeconomic factors, environment, developmental disabilities, Ecuador.

1 University of Michigan School of Public Health, Department of Epidemiology, Ann Arbor, Michigan, United States of America. Send correspondence to: Alexis J. Handal, 6100 Executive Boulevard, Room 7B03B, Rockville, Maryland 20852, United States of America; e-mail: handalal@mail. nih.gov; telephone: (301) 435-2295; fax: (301) 4022084.
2 University of Michigan, Center for Human Growth and Development and Department of Pediatrics and Communicable Diseases, Ann Arbor, Michigan, United States of America.

3 Centro de Estudios y Asesoría en Salud, Quito, Ecuador.
Development of the central nervous system (CNS) is a dynamic process that occurs as a cascade of events, with each step dependent on the completion of the previous step. The most rapid periods of CNS maturity in hu- 
mans occur in utero, during infancy, and at puberty. It is during these times that there is heightened susceptibility to the adverse effects of environmental toxins and other negative factors such as chronic malnutrition, nutrient deficiencies, and lack of developmental stimulation $(1,2)$.

As more children in the developing world survive their first years of life, attention must be paid to quality of life and neurobehavioral development during infancy and early childhood. Currently, there is limited data on this subject in developing countries. However, several health and sociodemographic predictors of delayed neurobehavioral development are common in the developing world and likely affect the neurobehavioral development of infants and young children. For example, research has shown associations between chronic malnutrition (i.e., stunting) (1, 3), iron-deficiency anemia (4-6), and low birthweight $(7,8)$ and delays in neurobehavioral development. In particular, deficits in nutrition are strongly associated with poorer gross and fine motor skills $(9,10)$. Developmental stimulation, which includes parental interactions with the child and interactions between children, is also important for optimal child development (11-13).

This paper describes the sociodemographic and nutritional characteristics associated with neurobehavioral development in children aged 3 to 61 months in three communities in the Cayambe-Tabacundo region of Ecuador, located approximately $53 \mathrm{~km}$ northeast of the capital city, Quito.

There is limited information on the neurobehavioral profile of young children in rural communities in the Ecuadorian highlands or the distribution of family characteristics most likely to affect child development. National health statistics for Ecuador reveal that $22.6 \%$ of children are born below their ideal birthweight, $26.0 \%$ of children under the age of 5 years suffer from chronic malnutrition, and $69.0 \%$ of infants under the age of 1 year suffer from anemia $(14,15)$. Therefore, many Ecuadorian children appear to be at risk for developmental delay. Maternal and family characteristics (e.g., maternal and paternal education, marital status, maternal age, household income, housing characteristics) have been shown to be associated with neurobehavioral development $(6,16-20)$.

\section{METHODOLOGY}

This study was conducted in 20032004 as a component of the EcoSalud Project, a joint undertaking between the Centro de Estudios y Asesoría en Salud (CEAS) in Quito, Ecuador and the International Development Research Centre (IDRC) in Ottawa, Canada. The EcoSalud Project, initiated in 2001 in the northeastern Andean region of Cayambe-Tabacundo, Ecuador, is a multidisciplinary investigation into the impacts of the cut-flower industry in the region. As a component of the epidemiologic section of EcoSalud, we studied children's neurobehavioral development.

The EcoSalud Project focused on four main clusters of communities. For this study, the sample was drawn from three communities located within the larger EcoSalud study region. Two communities were located at a lower altitude, closer to the industrial cutflower farms. These communities were situated approximately $10 \mathrm{~km}$ from each other, along the Pan-American Highway. The third community was located at a higher altitude and farther from the industrial agricultural zones, with fewer individuals who worked in the cut-flower industry. This community was located approximately 35 to $45 \mathrm{~km}$ from the two other study communities.

All mothers who had been living in the community for at least one year and had one or more children aged 3 to 61 months were eligible to participate. Up to three eligible children per mother were included in the study. Informed consent was obtained from the mothers, with consent requested for their participation as well as that of their children. Consent forms were read to the mother, and consent was documented by the mother's signature or fingerprint. In total, 219 eligible mothers $(91.3 \%$ of the total eligible mothers) and 283 eligible children (91.0\% of the total eligible children) participated. Approval for this preliminary study was obtained from the Institutional Review Board (IRB) at the University of Michigan as well as from CEAS in Quito, Ecuador.

The Ages and Stages Questionnaire (ASQ), a widely used developmental screening test, was directly administered to the child (Paul H. Brookes Publishing Co., Inc., Baltimore, Maryland, United States of America). Two trained testers assessed the participating children in all three communities. Following the ASQ, mothers were interviewed about their sociodemographic characteristics, maternal occupational history, maternal and child health characteristics, and the child's socialization profile. A finger-prick blood sample was obtained to assess the child's hemoglobin levels (i.e., anemia status) using the HemoCue hemoglobin blood testing kit (HemoCue, Inc., Lake Forest, California, United States of America). Height ( $\mathrm{cm})$, weight $(\mathrm{kg})$, and head circumference (cm) of the child were measured, as was the height and weight of the mother. Survey instruments were pretested and pilot tested to ensure clarity and comprehensibility. The kappa coefficient was calculated to assess the level of agreement between the two trained ASQ testers.

\section{Neurobehavioral development assessment}

The use of a parent report screening instrument has been shown to be an effective and valid way in which to assess a child's developmental progress (21). The ASQ is standardized for use in children aged 3 to 61 months and is composed of 19 age-specific questionnaires that cover a range of five broad developmental dimensions: (1) communication skills (vocalizing, listening, and understanding), (2) fine motor skills (hand and finger movements), (3) gross motor skills (arm, leg, and body movement), (4) problem-solving skills (learning and playing with toys), 
and (5) personal-social skills (solitary social play and play with other children). Each domain is scored from zero to 60 points, with 60 being a perfect score. A continuous score is calculated for each age-specific ASQ, with scores summarized for each developmental domain. Developmental delay is defined as being below two standard deviations (SDs) of the standardized score (22), with the cutoff values specific for each ASQ age interval.

Before administering the ASQ (Spanish version), the tool was adapted into the local vernacular, and contextually inappropriate questions were removed to prevent cultural and language bias. For example, all references to the baby/child were changed to the term "guagua," a Quichua term for baby or child commonly used in the region. Also, a question on the use of forks was removed, since the use of this utensil is not common practice in the region. In contrast to reliance solely on parent reporting, as is the more common procedure for ASQ administration, the tester attempted to directly elicit all ASQ behaviors from the child during the assessment, using the home visit procedure outlined in the ASQ manual (22). This procedure is more appropriate in a setting where the parent may not be able to complete the questionnaire on her own, as was the case in our study population. Testers brought all materials required for direct assessment as listed in the ASQ manual. Mothers were encouraged to participate in the activities with their child throughout the session. Maternal reporting of the child's behavior was only used when a particular activity could not be elicited or carried out at the time of the assessment.

\section{Measurement of nutritional and sociodemographic variables}

Standardized $z$-scores for anthropometric measures of chronic and acute malnutrition were calculated. These calculations use the 1978 Centers for Disease Control (CDC)/World Health Organization (WHO) growth reference curves, which are a normalized version of the 1977 National Center for

TABLE 1. Hemoglobin level cutoff values for the detection of anemia, based on altitude and age of child, in three rural Ecuadorian communities, Cayambe-Tabacundo region of Ecuador, 2003-2004

\begin{tabular}{lccc}
\hline Community & Altitude $(\mathrm{m})$ & Age of child $(\mathrm{yr})$ & $\begin{array}{c}\text { Hemoglobin level } \\
\text { cutoff values }(\mathrm{g} / \mathrm{dL})^{\mathrm{b}}\end{array}$ \\
\hline Community 1 & 2600 & $<2$ & $<12.3$ \\
Community 2 & 2900 & $2-5$ & $<12.5$ \\
Community 3 & $<2$ & $<12.6$ \\
& 3180 & $2-5$ & $<12.8$ \\
& $<2$ & $<13.0$ \\
\hline
\end{tabular}

a The sample in this study was drawn from three communities in the northeastern Andean region of Cayambe-Tabacundo, Ecuador. Two communities were located at a lower altitude, closer to the industrial cut-flower farms. The third community was located at a higher altitude and farther from the industrial agricultural zones, with fewer individuals who worked in the cut-flower industry.

${ }^{\mathrm{b}} \mathrm{g} / \mathrm{dL}=$ grams per deciliter.

Health Statistics (NCHS) growth reference curves (23). The z-score cutoff point for low anthropometric measures is two standard deviations (SDs) below the reference median for these indices. Chronic malnutrition (i.e., stunting) was defined as a low heightfor-age $z$-score, and acute malnutrition (i.e., wasting) was defined as a low weight-for-height $z$-score. Data on low birthweight $(<2500 \mathrm{~g})$ was obtained from the child's vaccine record card. If the mother did not have this card, she was asked directly. Presence of anemia (yes/no) was determined after taking into account the child's age and the altitude of the community of residence (24). Table 1 presents the cutoff values for anemia for the included communities.

Stimulation was assessed by two variables: (1) daily attendance at a daycare center (yes/no) and (2) the type and frequency of stimulating activities the mother was involved with at home with each child in the past three days. Day-care centers are located in all three communities and are managed by a local nongovernmental organization (Fundación Casa Campesina Cayambe) located in Cayambe. All the day-care centers follow a standardized protocol for the curriculum, including a standardized comprehensive developmental program. Each center is run by a trained child care educator and a trained health care promoter. Training is standardized for workers in all the region's day-care centers operated under the auspices of the foundation. To assess home support for child development, a set of six categories was adapted from a United National Children's Fund (UNICEF) multicountry survey (25). The six categories of activities between mother and child were: (1) reading to the child, (2) counting and/or drawing with the child, (3) looking at pictures (from any type of media), (4) singing songs, (5) going out of the house together, and (6) playing together. Each mother answered the questions based on her activities with the child and not whether an older sibling, a grandparent, or a neighbor did these activities.

Sociodemographic characteristics included mother's and father's education level (none/partial primary, completed primary school, or partial/ completed high school), mother's age, mother's ethnicity (indigenous, mestizo/white), mother's predominant language preference (Quichua/ Spanish mix, Spanish), marital status, monthly household income (US\$ 150 or less, US\$ 151-250, or > US\$250), and housing construction. Mother's education level was also used to assess literacy, since mother's education and ability to read were correlated $(r=$ 0.52 , $P$ value "0.001) as well as mother's education and ability to write ( $r=0.54, P$ value " 0.001). Father's education level was categorized similarly. Maternal age was examined as a con- 
TABLE 2. Mean score, standard deviation (SD), and frequency (\%) of delay in five developmental domains of the Ages and Stages Questionnaire (ASQ), stratified by age group ( $N=283$ ), Cayambe-Tabacundo region of Ecuador, 2003-2004

\begin{tabular}{|c|c|c|c|c|c|c|c|c|c|c|c|c|c|c|c|c|}
\hline \multirow[b]{2}{*}{$\begin{array}{c}\text { Age groups } \\
\text { (months) }\end{array}$} & \multirow[b]{2}{*}{$n^{\mathrm{a}}(\%)$} & \multicolumn{3}{|c|}{ ASQ communication } & \multicolumn{3}{|c|}{ ASQ gross motor } & \multicolumn{3}{|c|}{ ASQ fine motor } & \multicolumn{3}{|c|}{ ASQ problem-solving } & \multicolumn{3}{|c|}{ ASQ personal-social } \\
\hline & & Mean $^{b}$ & SD & $\begin{array}{c}\% \\
\text { delayedc }\end{array}$ & Mean & SD & $\begin{array}{c}\% \\
\text { delayed }\end{array}$ & Mean & SD & $\begin{array}{c}\% \\
\text { delayed }\end{array}$ & Mean & SD & $\begin{array}{c}\% \\
\text { delayed }\end{array}$ & Mean & SD & $\begin{array}{c}\% \\
\text { delayed }\end{array}$ \\
\hline $12-23$ & $70(24.7)$ & 32.9 & 16.1 & 51.4 & 36.4 & 16.3 & 30.0 & 38.8 & 11.8 & 22.9 & 42.7 & 12.8 & 12.9 & 44.9 & 12.8 & 7.1 \\
\hline $3-23$ & $123(43.5)$ & 35.2 & 14.2 & 35.8 & 35.5 & 15.6 & 30.1 & 39.1 & 13.7 & 21.1 & 40.5 & 13.3 & 18.7 & 41.3 & 13.6 & 15.5 \\
\hline $48-61$ & 64 (22.6) & 45.2 & 11.8 & 21.9 & 48.8 & 11.4 & 6.3 & 39.7 & 15.0 & 28.1 & 23.0 & 12.0 & 73.4 & 40.3 & 13.6 & 25.6 \\
\hline $24-61$ & $160(56.5)$ & 41.8 & 12.9 & 31.9 & 45.3 & 11.8 & 12.5 & 41.0 & 14.4 & 20.6 & 32.1 & 13.8 & 40.6 & 40.9 & 12.7 & 18.8 \\
\hline
\end{tabular}

${ }^{a} n=$ sample size.

${ }^{\mathrm{b}}$ Mean scores and standard deviations presented for each domain; higher score corresponds to better developmental skills.

c Developmental delay is defined as being below two standard deviations (SDs) of the mean standardized score, with the cutoff values specific for each ASQ age interval (Squires et al. (22)).

tinuous and a dichotomous variable based on the median (" 25 years old, $>25$ years old).

Housing characteristics, including roof composition (plastics, straw, zinc, tile, cement, brick, block), floor composition (dirt, wood, stone, tile, brick, cement), wall composition (plastics, adobe, mud, cement, brick, block), type of water used in home (river, lake, ditch, well, rain, piped, truck), bathroom type (none, outhouse, toilet), and access to electricity (yes/no), were summarized into a housing scale, with possible scores ranging from zero to seven. This housing construction scale was then categorized as poorer (three or less), mid-level (four to five), and better (six to seven), based on distribution quartiles.

We also examined socioeconomic status through a consideration of the social context of this particular region. ${ }^{4}$ We constructed a variable representing social position ("social insertion") based on the job of the principal economic provider of the family, since social position in this region is highly dependent on the job one holds. The five categories for this variable were: (1) works in the flower industry, (2) is a small business owner, (3) is in the mili-

\footnotetext{
4 Breilh J. New concepts and disagreements in the epidemiology of toxicology by agro-chemicals in the cut-flower industry [workshop presentation]. Workshop for the Development of the Health of CutFlower Workers, Quito, Ecuador, 23 August 2001.
}

tary, (4) works in salaried/sub-salaried manual labor (sub-salaried manual labor refers to irregular manual labor or marginal labor), or (5) is retired. There is not a defined hierarchy among these categories, but working in the flower industry is valued and does provide a higher income.

\section{Statistical analysis}

Developmental delay was analyzed within the appropriate age groups (3 to 23 months and 24 to 61 months) and was analyzed separately for each of the five developmental domains screened by the ASQ instrument. The mean score and frequency of developmental delay were calculated for children within each age group.

The mean score of developmental delay was compared across strata of each sociodemographic and health variable, and the associations between each covariate and specific developmental domains were examined within each age group using chi-square statistics. Given the relatively small sample size, we assessed both significant associations ( $P$ value " 0.05) and suggestive trends ( $P$ values 0.06 to 0.10$)$. Data were entered into SPSS 11.5 (SPSS Inc., Chicago, Illinois, United States) and were analyzed in SPSS and SAS Version 8 (SAS Institute Inc., Cary, North Carolina, United States). Nutritional data were analyzed in Epi Info's Nut-
Stat program software (Centers for Disease Control, Division of Public Health Surveillance and Informatics, Atlanta, Georgia, United States).

\section{RESULTS}

In total, 123 children in the younger age group ( 3 to 23 months) and 160 children in the older age group (24 to 61 months) were included in this analysis. Table 2 presents ASQ means for each developmental domain and frequency of developmental delay, by age group. Overall, more children were delayed in development of communication skills than in other domains, with similar percentages of delay between the younger and older age groups $(35.8 \%$ and $31.9 \%$, respectively), compared to a standardized United States population. Younger children, especially those under 24 months of age, showed more delay in their gross motor skills as compared to older children (30.1\% vs. $12.5 \%)$. Older children, specifically those 48 months and older, exhibited delay in development of problem-solving skills, with $73.4 \%$ scoring below the standardized cutoff point. Approximately $20.0 \%$ of children in both age groups showed delay in the development of fine motor skills, compared to a standardized United States population.

High frequencies of both anemia $(60.4 \%)$ and stunting $(53.4 \%)$ were 
found for the entire study population. Participants under 12 months of age had the highest prevalence of anemia $(77.4 \%), 70.9 \%$ of children younger than 36 months of age presented with anemia, and $43.5 \%$ of the study participants aged 36-61 month presented with anemia. Only $63.0 \%$ of the mothers were able to report a birthweight for their child. Of these $63.0 \%$, approximately $11.0 \%$ of children were born with low birthweight. Overall, over half $(57.8 \%)$ of the children were involved in stimulating activities at home with their mother. A much lower percentage of children $(13.6 \%)$ experienced these types of activities outside the home, specifically at a daycare center.

Most mothers in this population identified themselves as indigenous $(76.6 \%)$, although the majority reported their predominant language as Spanish $(88.7 \%)$. Over half of the mothers $(58.3 \%)$ reported being officially married, and another $25.4 \%$ of the women reported living with their significant other in a free union. The majority of mothers (59.4\%) reported having completed primary schooling. About half of the fathers (54.9\%) had completed primary schooling, and $27.4 \%$ of the fathers achieved partial or complete high school education. Note, however, that $16.3 \%$ of the mothers reported not having a husband/partner present in the household. Close to $50 \%$ of the mothers reported a monthly household income of US\$ 150 or less. Approximately half of the mothers also reported a mid-level housing construction value. Work in the flower industry was the most common employment reported for the principal economic provider of the family (38.2\%). In Table 3, sociodemographic and health characteristics of the study participants are presented for the entire study population.

For the age group of 3 to 23 months, low birthweight, low maternal education, and salaried/sub-salaried manual labor for the principal economic provider of the family were associated with lower communication skills. Stunting and low maternal education were associated with lower communi-
TABLE 3. Sociodemographic and health characteristics of the study population, including child, mother, and father ( $N=283$ ), Cayambe-Tabacundo region of Ecuador, 2003-2004

\begin{tabular}{|c|c|c|}
\hline Characteristics & $\begin{array}{l}\text { Number of } \\
\text { participants }\end{array}$ & $\%$ \\
\hline \multicolumn{3}{|l|}{ Child's age } \\
\hline 3-23 months & 123 & 43.5 \\
\hline 24-61 months & 160 & 56.5 \\
\hline \multicolumn{3}{|l|}{ Gender of child } \\
\hline Male & 150 & 53.0 \\
\hline Female & 133 & 47.0 \\
\hline \multicolumn{3}{|l|}{ Anemia } \\
\hline No & 112 & 39.6 \\
\hline Yes & 171 & 60.4 \\
\hline \multicolumn{3}{|l|}{ Stunting } \\
\hline No & 132 & 46.6 \\
\hline Yes & 151 & 53.4 \\
\hline \multicolumn{3}{|l|}{ Low birthweight } \\
\hline No data available & 104 & 36.7 \\
\hline No $(\geq 2500 \mathrm{~g})$ & 148 & 52.3 \\
\hline Yes $(<2500 \mathrm{~g})$ & 31 & 11.0 \\
\hline \multicolumn{3}{|l|}{ Daycare attendance (daily) } \\
\hline Yes & 39 & 13.8 \\
\hline No & 244 & 86.2 \\
\hline \multicolumn{3}{|c|}{ Stimulating activities with child at home (missing $=1$ ) } \\
\hline$\geq 3$ activities & 163 & 57.8 \\
\hline$<3$ activities & 119 & 42.2 \\
\hline \multicolumn{3}{|l|}{ Mother's age } \\
\hline$\leq 25$ years & 143 & 50.5 \\
\hline$>25$ years & 140 & 49.5 \\
\hline \multicolumn{3}{|l|}{ Ethnicity of mother (missing = 5) } \\
\hline Indigenous & 213 & 76.6 \\
\hline Mestizo/White & 65 & 23.4 \\
\hline \multicolumn{3}{|l|}{ Language most used } \\
\hline Spanish/Quichua mix & 32 & 11.3 \\
\hline Spanish & 251 & 88.7 \\
\hline \multicolumn{3}{|l|}{ Marital status } \\
\hline Single & 35 & 12.4 \\
\hline Separated/Widowed & 11 & 3.9 \\
\hline Free union & 72 & 25.4 \\
\hline Married & 165 & 58.3 \\
\hline \multicolumn{3}{|l|}{ Mother's education level } \\
\hline None or partial primary school & 70 & 24.7 \\
\hline Completed primary school & 168 & 59.4 \\
\hline Partial or completed high school & 45 & 15.9 \\
\hline \multicolumn{3}{|l|}{ Monthly household income in US\$ (missing = 2) } \\
\hline $0-150$ & 133 & 47.3 \\
\hline $151-250$ & 78 & 27.8 \\
\hline$>250$ & 70 & 24.9 \\
\hline \multicolumn{3}{|l|}{ Father absent } \\
\hline Yes & 46 & 16.3 \\
\hline No & 237 & 83.7 \\
\hline \multicolumn{3}{|l|}{ Father's education level $(n=237)$} \\
\hline None or partial primary & 42 & 17.7 \\
\hline Completed primary school & 130 & 54.9 \\
\hline Partial or completed high school & 65 & 27.4 \\
\hline \multicolumn{3}{|l|}{ Housing construction } \\
\hline Low & 56 & 19.8 \\
\hline Medium & 142 & 50.2 \\
\hline High & 85 & 30.0 \\
\hline \multicolumn{3}{|l|}{ Principal economic provider of family } \\
\hline Salaried/sub-salaried & 100 & 35.3 \\
\hline Small business owner, military, or retired & 75 & 26.5 \\
\hline Works in flower industry & 108 & 38.2 \\
\hline
\end{tabular}


cation skills in the older age group. Delayed development of gross motor skills was associated with stunting and low birthweight in the younger age group, while attendance at day care was associated with better gross motor skills in the older age group. Low birthweight was the only variable associated with poorer fine motor skills in the younger children, while in the older children, day-care attendance, increased stimulation at home, and younger maternal age were associated with higher fine motor scores. Mother's marital status showed an association with problem-solving skills in younger children, with single mothers displaying the lowest scores. In the older children, lowered stimulation, older maternal age, and lower maternal education were associated with poorer problem-solving skills. Surprisingly, anemia was associated with better communication and problemsolving skills in the older children. For the personal-social developmental domain, salaried/sub-salaried work for the principal economic provider of the family and lower child stimulation was associated with poorer social skills in the younger children. In the older age group, participating in fewer stimulating activities at home was significantly associated with lower social skill development. Neurobehavioral development did not differ by gender, ethnicity, preferred language, paternal education, or measures of socioeconomic status, including monthly income and housing construction. Table 4 presents the mean ASQ scores by health and sociodemographic characteristics, stratified by age.

\section{DISCUSSION}

This paper is one of the first to address patterns of delayed development in Ecuadorian infants and children living in a rural mountain region of the country and to consider the child health and sociodemographic factors that may be associated with developmental delay. Our results suggest a high prevalence of developmental delay in this population. We found children ages 1 year and older showed more delay in communication, children under 2 years of age showed more delay in gross motor development, and children 4 to 5 years of age showed more delay in fine motor and problem-solving skills, when compared to a standardized United States population. It should be noted that just under half of the population reported a low monthly household income and that nearly three quarters reported low or medium housing construction. Additionally, a majority of mothers and fathers did not attend or complete high school. These results suggest that our population may be distinct from a United States comparison population due to lower socioeconomic status and lower parental education. The results also suggest poor child nutritional status in this population, which may contribute to delayed development. Stimulation, including attendance at day care and increased maternal-child interaction at home, may support positive neurobehavioral development, specifically in terms of fine motor and social development.

In the United States, it is estimated that approximately $5.0 \%$ to $10.0 \%$ of children suffer from developmental delay (26). In developing countries such as Ecuador, data on developmental delay is scarce. However, data on the distribution of key predictors of delayed neurobehavioral development are available and can be useful in estimating the potential for delayed development in the population. Child health characteristics such as low birthweight, chronic malnutrition, and anemia are strong predictors of delayed development. In this rural mountain region of Ecuador, we found an overall percentage of low birthweight of $11.0 \%$, somewhat lower than the national estimate of $22.6 \%$ (14). Across all three communities included in the study population, there was a high prevalence of stunting $(53.0 \%)$, considerably higher than reported national estimates of chronic malnutrition of $26.0 \%$ for children under the age of 5 years (15). Finally, we observed a high, $60.0 \%$ frequency of anemia across all age groups. In Ecuador overall, the percentage of children who suffer from anemia is estimated at $69.0 \%$ for those 12 months of age or younger, $20.0 \%$ to $46.0 \%$ for those 36 months of age or younger, and $10.0 \%$ to $22.0 \%$ for those aged 36-61 months (15). Thus, the high prevalence of developmental delay in the study population is consistent with the poor health and nutritional status of the region's children, and we found the expected correlations between these health characteristics and developmental delay, with the exception of anemia.

Our results suggest a more complex association between presence of anemia and neurobehavioral development in older children. In general, the expected direction of association was found among stunting, low birthweight, and developmental delay. However, a positive association was found for anemia and both communication and problem-solving skills in the older children. Other unmeasured community-level factors may be confounding the relationship, or there may be mediating factors that impact the effect of anemia on development.

Another key factor important for optimal child development is a stimulating home environment. Our results indicate that a child who experienced greater stimulation at home through a variety of maternal-child activities displayed better developmental skills. These types of stimulating interactions provide the child with the opportunity to learn cognitive and socialization skills that further support his or her development. Day care may also provide the child with a stimulating environment. Our results suggest that attendance in day care promotes child development, especially with fine and gross motor skills. In all three participating communities, day care was available to the children of the community. The day-care centers had a comprehensive developmental program addressing all areas of development, including motor and cognitive skills. Differences in day-care attendance as well as the amount of stimulating activities provided in the home environment need to be considered 


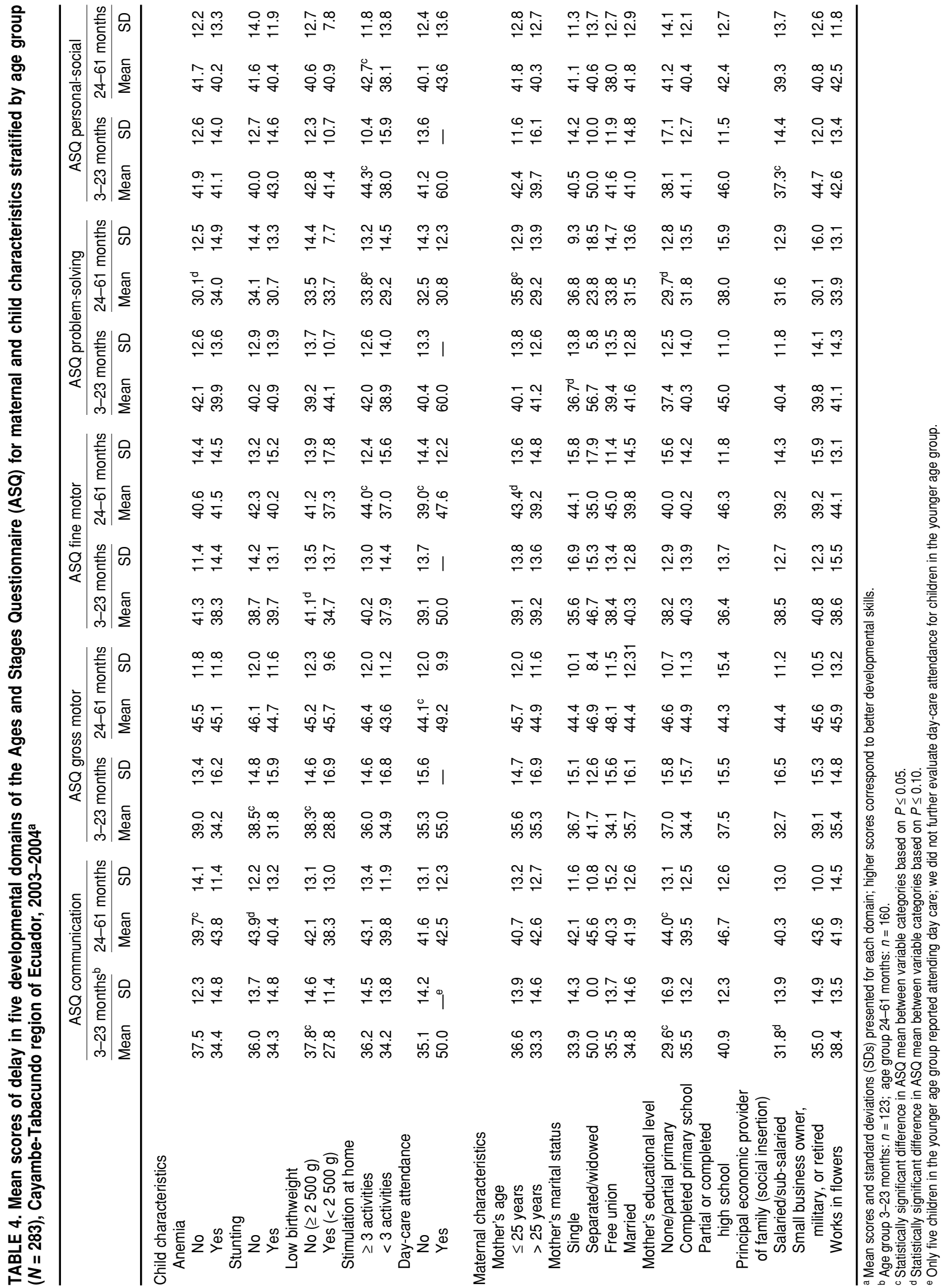


when examining patterns of developmental delay in this population. Interventions such as increased parentchild interaction and stimulation at home and the use of day care may be effective in optimizing child development in the region.

Stimulation, whether it occurred at home or in a day-care center, may have been influenced by other sociodemographic factors. For instance, the amount of stimulation a child received at home may have been dependent on the parents' work schedules or the amount of other responsibilities the mother faced at home. Day-care attendance was highly correlated with parental employment in the flower industry in this population. Our results suggest that other sociodemographic factors, such as partial or complete high school education for the mother and higher monthly household income, were also important for optimal neurobehavioral development.

Several limitations exist with the use of a general screening tool such as the ASQ. Despite our adaptation of the instrument into the local vernacular, the adaptation may not have been optimal for the cultural setting of the investigation. For example, several of the questions in both the problem-solving and the personal-social sections asked the child to repeat a set of numbers or a phrase. Shyness and reluctance to communicate with the interviewer may have led to an overestimation of delayed development. In future studies in this region, the sections of the ASQ that address social and cultural behaviors should be assessed carefully. Validation of these developmen- tal tools in this population and other similar cultures is needed. Another limitation of applying the ASQ in the population is the lack of standardized comparison data available for Ecuador. Differences in the conditions of the surrounding environment of the child, such as differences in economic and nutritional status, may affect neurobehavioral development differently in our population compared to a child residing in the United States; therefore, comparisons of our data to a standardized United States population may not be appropriate and should be interpreted with caution. Studies addressing the standardization of the ASQ or other similar developmental screening tools in Andean countries such as Ecuador are needed.

In our study, there was considerable nonresponse to questions about birthweight. However, our results are consistent with national data on the lack of reporting of an infant's birthweight to health authorities, in which only approximately $60 \%$ of mothers report or have access to information on their child's birthweight (14). In future studies, we would like to confirm birthweight for all study participants. Also, we would like account for the unique socioanthropological and cultural features present in this region of Ecuador by stratifying the population by appropriate social position categories ("social insertion").

Despite these limitations, this study provides much needed information on developmental delay and its social and environmental determinants in Ecuador, suggesting that developmental delay is a major concern among in- fants and young children in this region. This study also suggests that poor child health, specifically low birthweight and deficient growth and nutritional status, and an adverse surrounding environment (e.g., toxic exposures, adverse social/familial environments) of a child may contribute to developmental delay. This study highlights the need for continued focus on the issue of nutritional deficit in Latin American populations. The results of this study reinforce data presented by UNICEF in their May 2006 progress report on the nutritional status of the world's children, which suggested that stunting and iron-deficiency anemia in child populations in Latin America continue to be major challenges (27). Future analyses will explore the potential effects of pesticide exposure associated with large-scale agricultural industry on neurobehavioral development, taking into account the results of this analysis.

In summary, child development is a dynamic process that is affected by numerous factors, including parental involvement with the child, household relationships, maternal health (both physical and psychological), physical environment, and the child's physical and mental health. In researching potential risk factors that affect neurobehavioral development, recognition of the multifaceted determinants of delay is critical. Data on the population profile and correlates of neurobehavioral development provided in the present study will allow for a better understanding of factors that contribute to delayed neurobehavioral development in young Ecuadorian children.

\section{REFERENCES}

1. Delemarre-van de Waal HA. Environmental factors influencing growth and pubertal development. Environ Health Perspect. 1993;101 (Suppl 2):39-44.

2. National Research Council. Pesticides in the diets of infants and children. Washington, D.C.: National Academy Press; 1993.

3. Winick M. Cellular growth during early malnutrition. Pediatrics. 1971;47(6):969-78.
4. Stoltzfus RJ, Kvalsvig JD, Chwaya HM, Montresor A, Albonico M, Tielsch JM, et al. Effects of iron supplementation and anthelmintic treatment on motor and language development of preschool children in Zanzibar: double blind, placebo controlled study. BMJ. 2001;323(7326):1389-93.

5. Lozoff B, Jimenez E, Hagen J, Mollen E, Wolf AW. Poorer behavioral and developmental outcome more than 10 years after treatment for iron deficiency in infancy. Pediatrics. 2000; 105(4):E51.

6. Grantham-McGregor S, Ani C. A review of studies on the effect of iron deficiency on cognitive development in children. J Nutr. 2001; 131(2S-2):649S-666S.

7. Breslau N, Chilcoat H, DelDotto J, Andreski P, Brown G. Low birth weight and neurocog- 
nitive status at six years of age. Biol Psychiatry. 1996;40:389-97.

8. Breslau N, Paneth NS, Lucia VC. The lingering academic deficits of low birth weight children. Pediatrics. 2004;114(4):1035-40.

9. Benefice E, Fouere T, Malina RM, Beunen G. Anthropometric and motor characteristics of Senegalese children with different nutritional histories. Child Care Health Devel. 1996;22: 151-65.

10. Cheung YB, Yip PS, Karlberg JP. Fetal growth, early postnatal growth and motor development in Pakistani infants. Int J Epidemiol. 2001;30(1):66-72.

11. Sameroff AJ. Environmental risk factors in infancy. Pediatrics. 1998;102(5 Suppl E):1287-92.

12. Fendrich M, Warner V, Weissman MM. Family risk factors, parental depression, and psychopathology of offspring. Dev Psychol. 1990; 26(1):40-50.

13. Greenspan S. Developmental morbidity in infants in multirisk families. Public Health Rep. 1982;97(1):16-23.

14. Centro de Estudios de Población. ENDEMAIN99: Encuesta Demográfica y de Salud Materna e Infantil. Quito: CEPAR; 2000.

15. Pan American Health Organization. Health conditions in the Americas. 1998 ed. Washington, D.C.: PAHO; 1998. (Scientific Publication 569).
16. de Andraca I, Pino P, de la Parra A, Rivera F, Castillo M. Factores de riesgo para el desarrollo psicomotor en lactantes nacidos en óptimas condiciones biológicas. Rev Saude Publica. 1998;32(2):138-47.

17. DeGarmo DS, Forgatch MS, Martinez CR, Jr. Parenting of divorced mothers as a link between social status and boys' academic outcomes: unpacking the effects of socioeconomic status. Child Dev. 1999;70(5):1231-45.

18. Dollaghan CA, Campbell TF, Paradise JL, Feldman HM, Janosky JE, Pitcairn DN, et al. Maternal education and measures of early speech and language. J Speech Lang Hear Res. 1999;42(6):1432-43.

19. Hoff E. The specificity of environmental influence: socioeconomic status affects early vocabulary development via maternal speech. Child Dev. 2003;74(5):1368-78.

20. National Research Council and Institute of Medicine. From neurons to neighborhoods: the science of early childhood development. Washington, D.C.: National Academy Press; 2000.

21. Glascoe FP. Evidence-based approach to developmental and behavioural surveillance using parents' concerns. Child Care Health Devel. 2000;26(2):137-49.

22. Squires J, Potter L, Bricker D. The ASQ user's guide. 2nd ed. Baltimore: Brooks Publishing Co.; 1999.
23. Dibley MJ, Goldsby JB, Staehling NW, Trowbridge FL. Development of normalized curves for the international growth reference: historical and technical considerations. Am J Clin Nutr. 1987;46(5):736-48.

24. Centers for Disease Control. CDC criteria for anemia in children and childbearing-aged women. Morb Mortal Wkly Rep. 1989;38(22): 400-4.

25. United Nations Children's Fund. UNICEF indicators projects: family psychosocial care practices measures. New York: UNICEF; 2003. (Version 16).

26. Shevell M, Ashwal S, Donley D, Flint J, Gingold M, Hirtz D, et al. Practice parameter: evaluation of the child with global developmental delay: report of the Quality Standards Subcommittee of the American Academy of Neurology and the Practice Committee of the Child Neurology Society. Neurology. 2003;60 (3):367-80.

27. United Nations Children's Fund. Progress for children: a report card on nutrition. New York: UNICEF; 2006. (Report No.4).

Manuscript received 23 February 2006. Revised version accepted for publication 11 August 2006.
RESUMEN

Factores sociodemográficos y nutricionales relacionados con el desarrollo neuroconductual: estudio en niños pequeños de una zona rural de Ecuador

Palabras clave
Objetivos. Identificar y describir las características sociodemográficas y nutricionales asociadas con el desarrollo neuroconductual en niños pequeños de tres comunidades de la región nororiental andina de Cayambe-Tabacundo, Ecuador.

Métodos. Mujeres de las comunidades estudiadas con algún hijo de 3 a 61 meses de edad llenaron un cuestionario sobre sus características, las características de salud de su hijo y las características sociodemográficas. Dos entrevistadores entrenados aplicaron el Cuestionario sobre Edades y Etapas (Ages and Stages Questionnaire, ASQ) directamente a 283 niños. Se midió el crecimiento y se realizó una prueba de hemoglobina mediante punción digital en el período 2003-2004. Se calculó la prevalencia del retraso en el desarrollo y se exploraron las asociaciones entre el desarrollo del niño y las características de la madre, del niño y del hogar.

Resultados. Se observaron elevadas frecuencias de retraso en el desarrollo. Los niños de 3 a 23 meses de edad presentaron retraso en las habilidades motrices básicas $(30,1 \%)$ y los niños de 48 a 61 meses de edad presentaron retraso en las habilidades para solucionar problemas $(73,4 \%)$ y en las habilidades motrices finas $(28,1 \%)$. Se encontró una elevada frecuencia de anemia $(60,4 \%)$ y de retraso en el crecimiento $(53,4 \%)$ en todos los grupos de edad. Se observó una asociación directa entre el nivel educacional de la madre y las habilidades de comunicación y de solución de problemas de sus hijos, así como entre los ingresos mensuales del hogar y las habilidades de comunicación, las motrices básicas y de solución de problemas.

Conclusiones. Los resultados indican que hay una elevada prevalencia de retraso en el desarrollo y una deficiente salud infantil en la población estudiada. El estado de salud del niño y su entorno pueden contribuir al retraso en el desarrollo en esta región de Ecuador, sin embargo, los factores socioedemográficos que afectan negativamente a las oportunidades de estimulación pueden desempañar un papel importante en ello. Se requieren investigaciones que identifiquen las causas del elevado porcentaje de retraso en el desarrollo neuroconductual en esta región de Ecuador.

Epidemiología, desarrollo infantil, características de la población, factores socioeconómicos, ambiente, discapacidades del desarrollo, Ecuador. 